\title{
Measuring of the relative milk mass fraction in water-milk solution
}

\begin{abstract}
In this article the dependence of the output voltage of photo-receiver based on photodiode-operational amplifier pair from relative mass fraction of milk in water-milk solution, during infrared radiation is passaging through it, is received. The method for determining the optimum wavelength for providing maximum sensitivity of measuring the relative mass fraction of milk is created. The results of theoretical research are confirmed by an experiment.

Streszczenie. W artykule przedstawiono zależność napięcia wyjściowego foto-odbiornika opartego na parze wzmacniaczy z fotodiodami przy odbieraniu sygnału podczas promieniowania podczerwonego poprzez próbkę mieszaniny wody z mlekiem. Opracowana została metoda określania optymalnej długości fali dla zapewnienia maksymalnej czułości pomiaru względnej masy frakcji mleka. Wyniki badań teoretycznych zostały potwierdzone przez doświadczenia. (Pomiar względnej masy frakcji mleka w roztworze wody z mlekiem).
\end{abstract}

Keywords: stall milking machine, water-milk solution, infrared radiation, photo-receiver

Słowa kluczowe: dojarka mleka, roztwór wody z mlekiem, promieniowanie podczerwone, fotoodbiornik

\section{Introduction}

Stall milking machines, which are the most widely distributed on Ukrainian territory, provide machine milking of cows in stalls, transporting milk by means of milk line in the milk container, filtration of milk and its pumping from milk containers to the refrigerator or mixing machine using milk pump, measuring of milk yield, which is received by each milker. In such milking machines animals are divided into groups and refined in line along the milk line, there are four or eight such lines in a barn, each line is served by one milker, milking takes place using between two and four milking machines. Milk, obtained from each animal in the line, accumulates in the dispenser, located at the end of each line. After the milk of determined volume was accumulated in the dispenser, automatic drain valve triggeres and a portion is absorbed into the milk container, from which it enters the cooling or mixing machine $[1,2]$. Milker wages are calculated according to the number of portions of milk, which is formed by the dispenser, and which are calculated by special milk portion meters

Each milker has a bowl of water on stall milking machines, which is necessary to prepare the animals for milking. There are cases when milker, using machine, absorbs this water in the milk line to improve milk yield indices, which influences on his salary. Identifying these cases visually is very difficult, because human eye cannot distinguish the water-milk solution of pure milk. The same problem occurs when purchasing milk in small private farms. Dishonest providers dilute milk with water and pass it to the receiving station. Existing measuring parameters of milk are expensive and do not allow operational control of the availability of water in milk, and it is not possible to detect milker, which provides milk falsification with their help. Therefore, creating a method for rapid measurement of relative mass fraction of milk in water-milk solution is an important and urgent task.

\section{Analisys of studies}

Nowadays, to identify the facts of falsification of milk in the lab the measuring control of its freezing temperature is used [3]. This method cannot be used to stall milking machines during milking.
At stall milking installations with milk line, milk portions meters are used with the sensor, the principle of which follows [4]. After passing a portion of milk from the dispenser through the drain valve, the milk enters the flexible hose. Inside of the hose there is a tube with mounted electrodes. With the passage of portions of milk through a tube between the electrodes the electrical conductivity changes, which is a sign for dispenser to operate. If you change the conductivity, sensor generates a voltage signal that is directly proportional to the value of conductivity. If the milk contains the water, and the temperature changes, and milk foams, the initial conductivity conversion error significantly increases. The water in the milk leads to a decrease of its conductivity, but, due to the presence of the above factors, revealing a slight dilution of milk is impossible.

Also to count the portions of milk they use optical sensor [4], the principle of which follows. A portion of the milk passes through the tube, which is integrated with infrared LED and an infrared phototransistor, which operates in key mode. With the passage of portions of milk the light flow interrupts, therefore an impulse of the determined duration forms in the output of phototransistor. Basing on the measurement of output signal of phototransistor, the fact of passing of portions of milk is established. When there is a large amount of water in the milk, the luminous flow passes through it with little loss of power. As a result, a portion of milk is not counted, but finding a small amount of water in the milk using the aforementioned sensor is also impossible.

\section{Problem formulation}

To further creation of a mean of measuring operational control of presence of water in the milk, we need to obtain the dependence of the output voltage of photo-receiver based on photodiode-operational amplifier pair, from the relative mass fraction of milk in water-milk solution, when the infrared radiation passes through solution. To maximize the sensitivity of an aforementioned mean of measuring operational control, we must create a method for determining the optimum wavelength of infrared radiation. The results of theoretical research are necessary to confirm by the results of the experiment. 


\section{Main part}

The weakening of monochromatic radiation substance is determined by Beer-Lambert-Bouguer law, that binds the input and output intensity of the optical radiation as it passes through substance [5]

$$
I=I_{0} e^{-\alpha c d}
$$

where $I_{0}$ - the intensity of radiation, that falls on substance; $d$ - thickness of a layer; $c$ - concentration of the substance; $\alpha$ - attenuation coefficient.

Beer-Lambert-Bouguer law can be written using decimal logarithms

$$
I=I_{0} \cdot 10^{-k(\lambda) c d}
$$

where $k(\lambda)$ - extinction coefficient, which is a function of the wavelength of optical radiation $\lambda$.

Skipping by substance the radiation is characterized by transmittance, defined as

$$
K_{P R}(\lambda)=\frac{I}{I_{0}}=10^{-k(\lambda) c d} .
$$

An important characteristic of the substance is its optical density, determined by the expression

$$
D(\lambda)=\lg \frac{I_{0}}{I}=k(\lambda) c d .
$$

Passing through a solution of the components, radiation by each of them is absorbed in different ways. The resulting absorption is derived by additive superposition of individual components. Accordingly, the optical density $n$ component mix is determined by the expression

$$
D(\lambda)=\sum_{i=1}^{n} k_{i}(\lambda) c_{i} d
$$

where $k_{i}(\lambda)$ - extinction coefficient of $i$ - component of the mix; $c_{i}$ - concentration; $i$ - component of the mix.

For the water-milk solution $n=2$, accordingly, its optical density is determined by the expression

$$
D_{V M}(\lambda)=d\left(k_{M}(\lambda) c_{M}+k_{V}(\lambda) c_{V}\right),
$$

where $k_{M}(\lambda)$ - milk extinction coefficient; $c_{M}$ concentration of the milk in water-milk solution; $k_{V}(\lambda)$ water extinction coefficient; $c_{V}$ - concentration of the water in water-milk solution.

The volume of water-milk solution, that absorbs radiation, is given by

$$
V_{K}=V_{M}+V_{V}=\frac{m_{M}}{\rho_{M}}+\frac{m_{V}}{\rho_{V}},
$$

where $m_{M}$ - mass of the milk in water-milk solution; $\rho_{M}$ density of milk; $m_{V}$ - mass of the water in water-milk solution; $\rho_{V}$ - density of water.

Concentration of the water in water-milk solution defined as

(8) $c_{V}=\frac{m_{V}}{V_{K}}=\frac{m_{V}}{\frac{m_{M}}{\rho_{M}}+\frac{m_{V}}{\rho_{V}}}=m_{V} \frac{\rho_{M} \rho_{V}}{m_{M} \rho_{V}+m_{V} \rho_{M}}$.

Concentration of the milk in water-milk solution

$$
\text { (9) } c_{M}=\frac{m_{M}}{V_{K}}=\frac{m_{M}}{\frac{m_{M}}{\rho_{M}}+\frac{m_{V}}{\rho_{V}}}=m_{M} \frac{\rho_{M} \rho_{V}}{m_{M} \rho_{V}+m_{V} \rho_{M}} \text {. }
$$

The relative mass fraction of milk in water-milk solution is defined as

$$
\eta=\frac{m_{M}}{m_{M}+m_{V}}
$$

From the expression (10), after simple transformations, we get

$$
m_{V}=m_{M}\left(\frac{1}{\eta}-1\right)
$$

Substituting (11) to (8) and (9), after transformations we obtain expressions that link the concentration of milk and water in the milk-water solution with relative mass fraction of milk.

$$
c_{V}=\frac{\rho_{M} \rho_{V}\left(\frac{1}{\eta}-1\right)}{\rho_{V}+\rho_{M}\left(\frac{1}{\eta}-1\right)},
$$

Substituting (12) and (13) to (6), and after transformations we obtain the dependence of the optical density of the water-milk solution from the relative mass fraction of milk

$$
D_{V M}(\lambda)=\frac{d \rho_{M} \rho_{V}\left(k_{M}(\lambda)+k_{V}(\lambda)\left(\frac{1}{\eta}-1\right)\right)}{\rho_{V}+\rho_{M}\left(\frac{1}{\eta}-1\right)} .
$$

In view of (4), after transformations we obtain

$$
I=I_{0} \cdot 10
$$

$$
-\frac{d \rho_{M} \rho_{V}\left(k_{M}(\lambda)+k_{V}(\lambda)\left(\frac{1}{\eta}-1\right)\right)}{\rho_{V}+\rho_{M}\left(\frac{1}{\eta}-1\right)} .
$$

Expression (15) is a mathematical model of optical radiation absorption by water and milk solution. This expression links the intensity of optical radiation passing through the solution with relative mass fraction of milk in solution. According to $[6,7]$, the output voltage of photoreceiver, based on photodiode-operational amplifier pair, in a first approximation is given by

$$
U_{F}=I S_{I 0}(\lambda) R_{Z Z} S_{V D},
$$

where $S_{V D}$ - square of photosensitive layer of photodiode; $S_{I 0}(\lambda)$ - spectral sensitivity of photodiode; $R_{Z Z}$ resistance in the feedback loop of the operational amplifier. Substituting (15) in (16) and obtain the dependence of the output voltage of photo-receiver, based on photodiodeoperational amplifier pair, from the relative mass fraction of milk in water-milk solution.

(17) $U_{F}(\eta)=I_{0} S_{I 0}(\lambda) R_{Z Z} S_{V D} \cdot 10$

$$
-\frac{d \rho_{M} \rho_{V}\left(k_{M}(\lambda)+k_{V}(\lambda)\left(\frac{1}{\eta}-1\right)\right)}{\rho_{V}+\rho_{M}\left(\frac{1}{\eta}-1\right)}
$$

Solving the equation (3.103) as concerns $\eta$, obtain an expression that links the relative mass fraction of milk in water-milk solution with an output voltage of photo-receiver, based on photodiode-operational amplifier pair 
(18)

$$
\eta=\frac{\rho_{M} \lg \frac{U_{F}(\eta)}{I_{0} S_{I 0}(\lambda) R_{Z Z} S_{V D}}+d \rho_{M} \rho_{V} k_{V}(\lambda)}{\left(\rho_{M}+\rho_{V}\right) \lg \frac{U_{F}(\eta)}{I_{0} S_{I 0}(\lambda) R_{Z Z} S_{V D}}+d \rho_{M} \rho_{V}\left(k_{V}(\lambda)-k_{M}(\lambda)\right)}
$$

Infrared spectrometry is widely used for quality control of foodstuffs $[5,8]$. Milk and milk-water solution refer to substances with a significant degree of absorption of infrared radiation in the near region of the spectrum, characterized by wavelengths of 0.75 to $2.5 \mu \mathrm{m}$ [5]. This fact leads to high sensitivity of means of measuring the mass fraction of milk in the water-milk solution, based on infrared spectrometry methods.

Fig. 1 shows typical experimental spectral transmission characteristics of infrared radiation of near areas of spectrum for milk and water, which thickness is $d=10 \mathrm{~mm}$ [5].

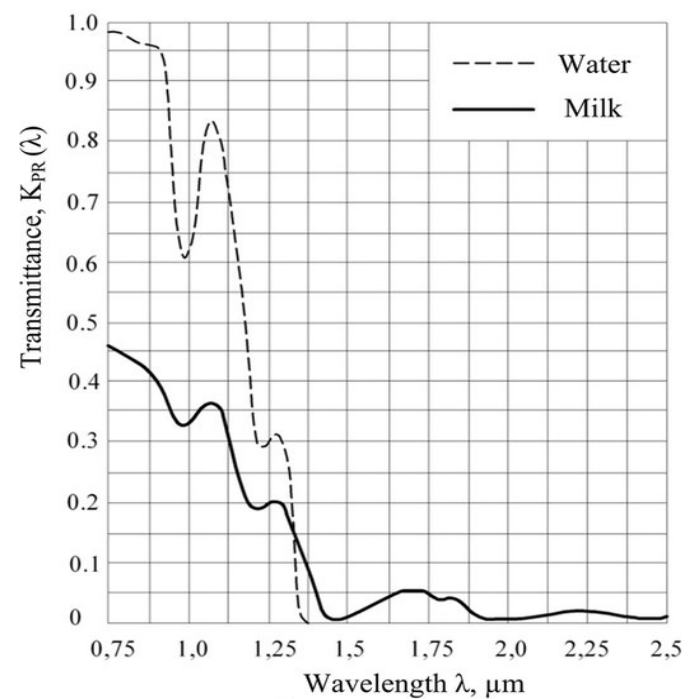

Fig. 1. Typical experimental spectral characteristics of transmission of infrared radiation for milk and water, thickness of which is $\mathrm{d}=10 \mathrm{~mm}$

The spectral transmittance characteristics of substance is the dependence of transmittance, defined by (3), from the wavelength of the optical radiation. Extinction coefficient and transmittance are connected by the dependence

$$
k(\lambda)=-\frac{1}{c d} \lg K_{P R}(\lambda)
$$

It should be noted, that the shape of the spectral transmission characteristics is highly dependent on the thickness of matter $d$. The mathematical expression, that describes a spectral transmission characteristic, can be obtained only by interpolation results of experimental data. Let's find the optimum wavelength of optical radiation, when the sensitivity of mean of the measurement will be maximum. It is clear, that sensitivity will be maximum at the wavelength, at which ratio of transmittance of water to milk transmission ratio will be maximized. In this case the maximum reduction of the absorption of infrared radiation by milk is provided, due to the presence of water.

To determine the optimum value of wavelength of infrared radiation, let's hold interpolation of spectral transmission characteristics of infrared radiation near spectrum areas for milk and water. We know that high quality results of interpolation are achieved with cubic spline function, which consists of pieces of cubic polynomials, with using which pulsations of interpolating function are not possible [9]. Cubic splines are cubic parabola, which, in each case, are just passing through two control points, which are determined from experimental spectral characteristics. Thus, the spectral transmittance characteristics of infrared radiation of near areas of the spectrum for milk can be represented as an interpolating function

$$
K_{P R M}(\lambda)=\left\{\begin{array}{l}
a_{1 M}+b_{1 M}\left(\lambda-\lambda_{1}\right)+c_{1 M}\left(\lambda-\lambda_{1}\right)^{2}+ \\
+d_{1 M}\left(\lambda-\lambda_{1}\right)^{3}, \quad \lambda \in\left[\lambda_{1}, \lambda_{2}\right] \\
a_{2 M}+b_{2 M}\left(\lambda-\lambda_{2}\right)+c_{2 M}\left(\lambda-\lambda_{2}\right)^{2}+ \\
+d_{2 M}\left(\lambda-\lambda_{2}\right)^{3}, \quad \lambda \in\left[\lambda_{2}, \lambda_{3}\right] ; \\
\ldots \\
a_{N-1 M}+b_{N-1 M}\left(\lambda-\lambda_{N-1}\right)+ \\
+c_{N-1 M}\left(\lambda-\lambda_{N-1}\right)^{2}+ \\
+d_{N-1 M}\left(\lambda-\lambda_{N-1}\right)^{3}, \quad \lambda \in\left[\lambda_{N-1}, \lambda_{N}\right] ;
\end{array}\right.
$$

where $a_{i M}, b_{i M}, c_{i M}, d_{i M}$ - coefficients of interpolating splines.

The spectral characteristic of transmittance of infrared radiation of near areas of the spectrum for water can be written as

$$
K_{P R V}(\lambda)=\left\{\begin{array}{l}
a_{1 V}+b_{1 V}\left(\lambda-\lambda_{1}\right)+c_{1 V}\left(\lambda-\lambda_{1}\right)^{2}+ \\
+d_{1 V}\left(\lambda-\lambda_{1}\right)^{3}, \quad \lambda \in\left[\lambda_{1}, \lambda_{2}\right] \\
a_{2 V}+b_{2 V}\left(\lambda-\lambda_{1}\right)+c_{2 V}\left(\lambda-\lambda_{1}\right)^{2}+ \\
+d_{2 V}\left(\lambda-\lambda_{1}\right)^{3}, \quad \lambda \in\left[\lambda_{2}, \lambda_{3}\right] \\
\ldots \\
a_{N-1 V}+b_{N-1 V}\left(\lambda-\lambda_{1}\right)+ \\
+c_{N-1 V}\left(\lambda-\lambda_{1}\right)^{2}+ \\
+d_{N-1 V}\left(\lambda-\lambda_{1}\right)^{3}, \quad \lambda \in\left[\lambda_{N-1}, \lambda_{N}\right]
\end{array}\right.
$$

where $a_{i V}, b_{i V}, c_{i V}, d_{i V}$ - coefficients of interpolating splines.

To determine the optimal wavelength, for which the ratio of water transmittance to milk transmittance will be maximized, let's find the ratio of function (21) to (20)

$$
K_{P R M V}(\lambda)= \begin{cases}\frac{a_{1 V}+b_{1 V}\left(\lambda-\lambda_{1}\right)+c_{1 V}\left(\lambda-\lambda_{1}\right)^{2}+d_{1 V}\left(\lambda-\lambda_{1}\right)^{3}}{a_{1 M}+b_{1 M}\left(\lambda-\lambda_{1}\right)+c_{1 M}\left(\lambda-\lambda_{1}\right)^{2}+d_{1 M}\left(\lambda-\lambda_{1}\right)^{3}}, & \lambda \in\left[\lambda_{1}, \lambda_{2}\right] ; \\ \frac{a_{2 V}+b_{2 V}\left(\lambda-\lambda_{1}\right)+c_{2 V}\left(\lambda-\lambda_{1}\right)^{2}+d_{2 V}\left(\lambda-\lambda_{1}\right)^{3}}{a_{2 M}+b_{2 M}\left(\lambda-\lambda_{1}\right)+c_{2 M}\left(\lambda-\lambda_{1}\right)^{2}+d_{2 M}\left(\lambda-\lambda_{1}\right)^{3}}, & \lambda \in\left[\lambda_{2}, \lambda_{3}\right] ; \\ \ldots & \\ \frac{a_{N-1 V}+b_{N-1 V}\left(\lambda-\lambda_{1}\right)+c_{N-1 V}\left(\lambda-\lambda_{1}\right)^{2}+d_{N-1 V}\left(\lambda-\lambda_{1}\right)^{3}}{a_{N-1 M}+b_{N-1 M}\left(\lambda-\lambda_{1}\right)+c_{N-1 M}\left(\lambda-\lambda_{1}\right)^{2}+d_{N-1 M}\left(\lambda-\lambda_{1}\right)^{3}}, & \lambda \in\left[\lambda_{N-1}, \lambda_{N}\right] ;\end{cases}
$$


At the optimum wavelength of the infrared radiation there is the relation

$$
K_{P R M V}\left(\lambda_{O P T}\right)=\max _{\left[\lambda_{1}, \lambda_{N}\right]} K_{P R M V}(\lambda)
$$

Thus, finding the optimum wavelength is reduced to solving the standard problem of determining the maximum of function (22). On fig. 2, a, there are the results of interpolation using cubic splines of spectral transmission characteristics of water and milk, which are on 1, and on fig. $2, \mathrm{~b}$ - a graph of the function described by (22).

As follows from Fig. 2, the optimum wavelength of infrared radiation for determining the relative mass fraction of milk in water-milk solution at $10 \mathrm{~mm}$ is about $0.91 \mu \mathrm{m}$. In accordance with (17), to ensure a minimum threshold of sensitivity, it is desirable to maximize approximation wavelength, which corresponds to the maximum of spectral characteristics of the photodiode, to the optimum wavelength of infrared radiation. In other words, ideally, there must be performed the ratio

$$
\lambda_{0}=\lambda_{O P T} \text {. }
$$

At the fig. 3 , a there is theoretical dependencies family $U_{F}(\eta)$ of output voltage of photo-receiver, based on photodiode-operational amplifier pair, from the relative mass fraction of milk in water-milk solution at different values of the intensity of infrared radiation. The above

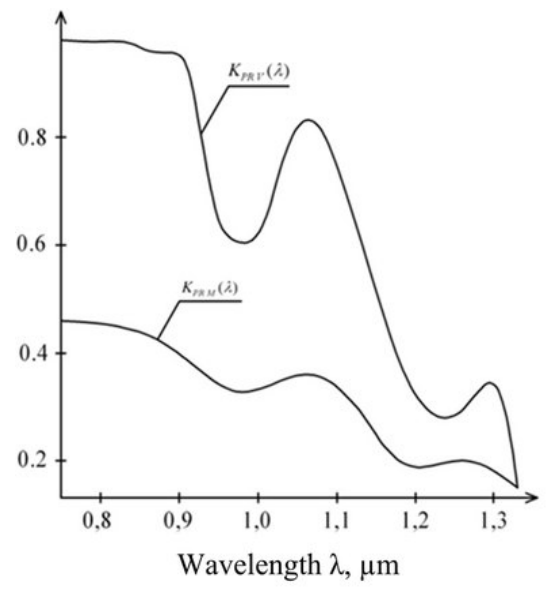

a) dependencies are defined by the expression (17), the value of $I_{0}$ during their construction chosen so as to ensure equality of theoretical and experimental values at zero relative mass fraction of milk in water-milk solution. Fig. $3, b$ shows a graph of experimental dependence $U_{F E}(\eta)$ of the output voltage of photo-receiver, based on photodiodeoperational amplifier pair, from the relative mass fraction of milk in water-milk solution at different values of current of infrared LEDs, which correspond to different values of the intensity of infrared radiation.

In experimental studies, as the radiator is used IR LED EL IR11-21C manufactured by Everlight Americas Inc, which has a nominal wavelength of the infrared radiation of $0.94 \mu \mathrm{m}$ and a maximum current of $100 \mathrm{~mA}$. Photo-receiver, based on photodiode-operational amplifier pair was implemented on photodiode S1336-18BQ manufactured by Hamamatsu Photonics, whose spectral characteristics has a maximum at a wavelength of radiation of 0.96 microns, and which at this wavelength has integrated current sensitivity of $0.5 \mathrm{~A} / \mathrm{W}$. A certain difference between the experimental and theoretical data is caused by the fact that in the expression (17) it's not taken into account that there are the reflection of infrared radiation from the water-milk solution, radiation diffraction and its scattering in fat balls in solution, not a monochromatism of sources of radiation.

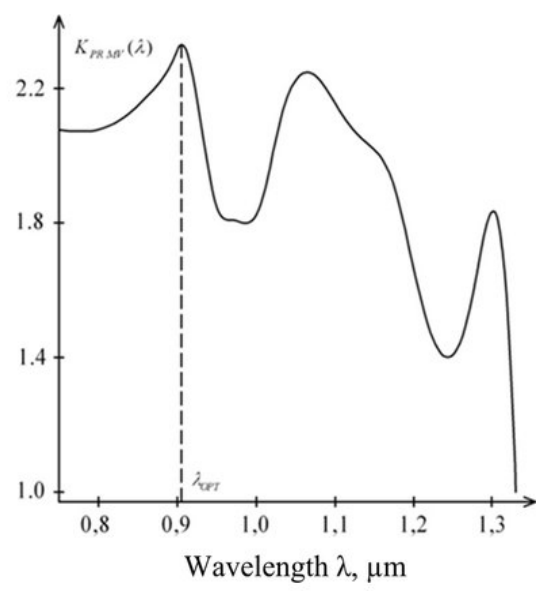

b)

Fig. 2. Results of interpoiatıon оा spectraı transmıssıon cnaracterısıcs oा water ana mıा ana grapn оा tne ratıo of their interpolating functions. $a$ - interpolating functions of spectral transmission characteristics of water and milk; $b$ - the ratio of interpolating functions of spectral transmission characteristics of water and milk

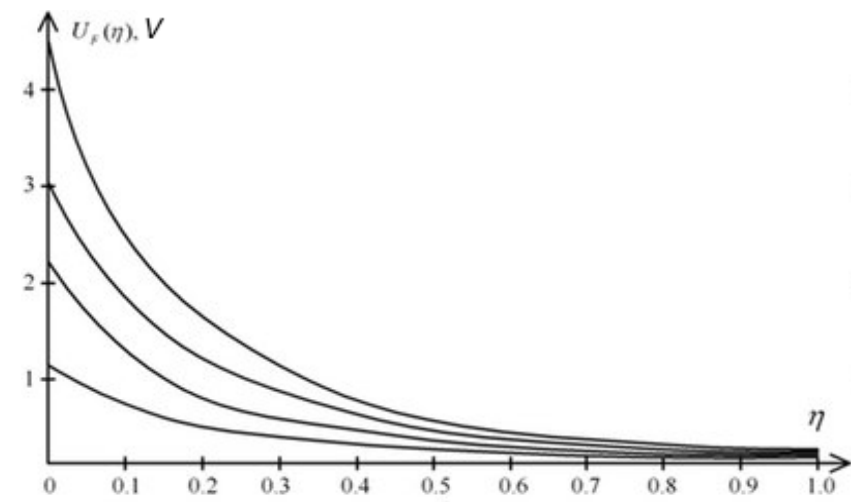

a)

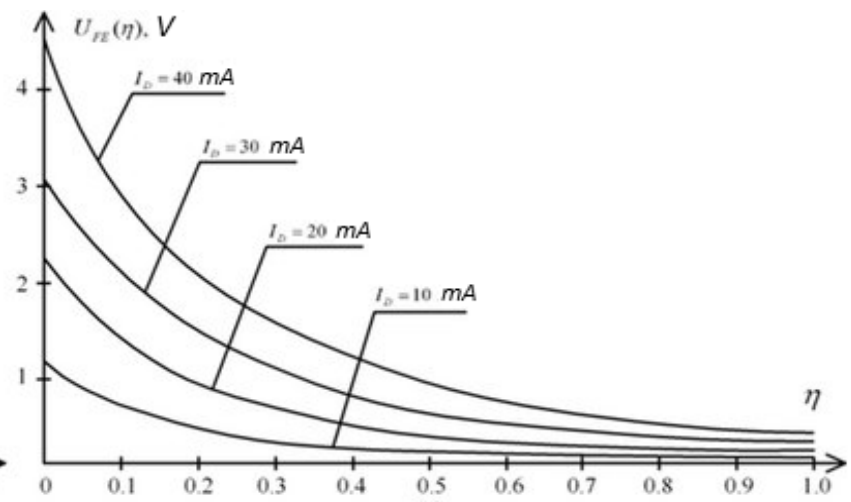

b)

Fig. 3. Family of theoretical and experimental dependencies of the output voltage of photo-receiver, based on photodiode-operating amplifier pair from the relative mass fraction of milk in water-milk solution at different values of the intensity of infrared radiation. a - a family of theoretical dependencies; $b$ - a family of experimental dependencies 


\section{Conclusions}

In the process of theoretical studies, we obtained the dependence of photo-receiver output voltage, based on photodiode - operational amplifier pair, from the relative mass fraction of milk in water-milk solution. Based on the above dependence it's possible to implement the mean of measuring control of the presence of water in the milk during the milking at stall milking facilities in order to reveal the falsification of milk by milkers. We proposed the method of determining the optimum, for measuring the relative mass fraction of milk, wavelength of infrared radiation, which passes through the water-milk solution. The adequacy of the obtained theoretical results is confirmed by experimental research.

Authors: Volodymyr Kucheruk, DSc, Prof.; Evgen Palamarchuk, PhD; Pavel Kulakov, DSc; Natalia Storozhuk, Department of Metrology and industrial automation, Vinnytsia National Technical University, 95 Khmelnitskoye Shosse, Vinnytsia, 21021, Ukraine, E-mail: volodymyr.kucheruk@gmail.com; Waldemar Wójcik, Lublin University of Technology, Nadbystrzycka 38A, 20618 Lublin, Poland; Maral Zhassandykyzy, Kazakh National Research Technical University after K.I. Satpaeva, 22 Satbaev Street, 050013, Almaty City, Kazakhstan
[1] http://bratslav.com/

[2] Tsoy Y.A., Processes and equipment of milking and dairy cattles of farms. GNU VIESH, Moscov 2010

[3] Tepel A., Chemistry and physics of milk. Food processing industry, Moscov 1979

[4] Milking machine UDM-200. Technical description and operating instructions. Bratslav. 2002

[5] Avramenko V.N., Eselson M.P., Zaika A.A., Infrared spectra of foodstuffs. Food processing industry, Moscov 1974

[6] Kucheruk V.Y., Palamarchuk Y.A., Kulakov P.I., Gnes T.V., Blohin Y.Y., Photoelectrical measuring conversion of area-voltage. Optoelectronic Information and Energy Technologies, 1(27) (2014), 139-145

[7] Vasilevskiy O.M., Kulakov P.I., Elements of the theory of increasing the measurement accuracy and synchronization of rotor angular velocity interconnected with electric motors, VNTU, Vinnitsia 2011

[8] Borovikov A.S., Vaynberg E.I., Gorbunov V.I. and others, Gears for non-destructive control of materials and products. Engineering, Moscov 1986

[9] Zavyalov Y.S., Kvasov B.I., Miroshnichenko V.L., Methods of spline functions. Science, Moscov 1980

[10]Pukach A., Teslyuk V., Ivantsiv R.A., Komada P., Method and means of measuring small quantities of electrical resistance. Informatyka, Automatyka, Pomiary w Gospodarce i Ochronie Środowiska, 4b (2012), 14-16 